\title{
VAT on Intra-Community Trade and Bilateral Micro Revenue Clearing in the EU
}

\author{
Christian Breuer \\ Chang Woon Nam
}

CESIFO WORKING PAPER NO. 2771

CATEgory 1: Public Finance

August 2009

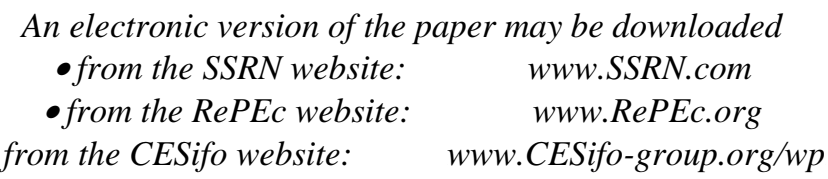




\title{
VAT on Intra-Community Trade and Bilateral Micro Revenue Clearing in the EU
}

\begin{abstract}
This study discusses European Commission's recent proposal to combat VAT fraud by taxing intra-Community supplies at a common rate of $15 \%$, accompanied by the internal correction of input-tax gap between an importer and his own national tax authority, which is caused by the national VAT rate differing from $15 \%$. It attempts to put this proposal into perspective by linking it to the overall aims of value added taxation in Europe and by comparing it to other alternative mechanisms examined in the literature. Especially issues of bilateral VAT revenue clearing between EU countries, which arise from the Commission's proposal, are highlighted.

JEL Code: H87, H20.

Keywords: value added tax, intra-EU trade, bilateral micro clearing, VAT fraud, European Union.

Christian Breuer

Ifo Institute for Economic Research at the University of Munich

Poschingerstrasse 5

81679 Munich

Germany

breuer@ifo.de

Chang Woon Nam

Ifo Institute for Economic Research at the University of Munich

Poschingerstrasse 5

81679 Munich

Germany

nam@ifo.de
\end{abstract}




\section{Introduction}

According to the basic principle of the EU VAT Directive, the common EU VAT regime should ideally be neutral concerning the origin of goods and their stage of production or distribution, so that a single market which guarantees fair competition can be realised. At the same time a business in the EU which has a full right to deduct should be unaffected by the taxation of intra-EU trade, and would apply the same principle to cross-border purchases as it does to domestic ones, and pay the VAT due to its supplier and reclaim this as input tax on its VAT return.

Despite the introduction of the single market and the abolition of border controls in 1993, the destination principle still applies for the cross-border trade between firms in the EU, which are taxed with the zero-rate. ${ }^{1}$ Since 1993 the member states must monitor the proper rebate of VAT credits for intra-EU supplies to and the proper payment of VAT on intra-EU acquisitions from other members by checking the books of registered enterprises. ${ }^{2}$ Apart from the compliance asymmetry - the different VAT treatment of domestic and cross-border supplies - which cause non-symmetric compliance costs, the prevailing transitional VAT system has been criticised since the deferred payment system breaks the VAT chain at the borderline of domestic and foreign tax administration (European Commission 1996; Lockwood, de Meza and Myles 2005). It was expected that such weaknesses in VAT control would be exploited by VAT frauds, given the fact that in the EU there has always been a permanent and huge flow of commodities which circulate free of VAT after the export VAT rebate in the exporting country has been granted and before the deferred VAT payment in the importing country becomes effective (see also Genser 2003; Cnossen 2008b). ${ }^{3}$ "Goods allegedly destined for export (at which prior stage VAT had been refunded) might be re-imported and diverted to the shadow economy, and imported goods (which would leave another member state free of VAT) might not be included in

1 The Draft Directives of 1987 and 1989 which stipulated VAT rate bands and revenue distribution through cross-border VAT crediting in conjunction with a tax clearing mechanism did not find unanimous support in the European Council. For this reason, such a transitional VAT system was then implemented by the Directives 91/680/EEC and 92/77/EEC. Yet the origin principle applies to the direct imports of households, although for some specific cases (including household purchase of cars) the destination principle still prevails. In addition an EU-wide minimum VAT standard rate of $15 \%$ was introduced.

2 In this context VAT identification numbers were introduced to identify registered business from other member countries, and firms were obliged to provide detailed information on the intra-EU trade under the VAT Information Exchange System and Intrastat system.

3 In 2006 with over two and a half million businesses across the EU, intra-EU purchases reached over $€ 2,400$ billion. In addition, for the majority of member states the value of intra-EU supplies of goods has recently accounted for around $10 \%$ to $20 \%$ of their total supplies (European Commission 2008). 
the importer's VAT return. [Even more seriously], a chain of artificial transactions from the import to the export stage could be created resulting in net VAT funds being paid without VAT ever having been collected in previous stages, a phenomenon which goes by the name of carousel fraud” (Cnossen 2008a: p. 3). More precisely the carousel fraud also called missing trader intra-Community (MTIC) fraud - takes place when "fraudsters register for VAT, buy goods [tax]-free from another member states, sell them on at VAT inclusive prices and then disappear without paying the VAT due” (Cnossen 2008a: p. 16).

In order to solve the problems surrounding such carousel frauds caused by the break in the VAT-collection chain, several reform proposals for the future European VAT system have been made in the literature (Bird and Gendron 2000; Genser 2003). According to the viable integrated VAT (VIVAT) recommended by Keen and Smith (2000), for example, a common Euro-VAT rate is imposed on all the business-to-business (B2B) cross-border supplies between the EU member states (the so-called exporter rating), whereas a national retail sales tax is charged on sales to final consumers. Since the Euro-VAT rate is the same throughout the EU, a multilateral clearing can be used to fill the revenue gaps caused by the difference between intra-EU supplies and acquisitions of the individual countries. However, such a uniform exporter rating does not provide the solution of problems related to "the break in the VAT-audit trail. Importing member states would still not be able to audit importers' invoices (received from exporters in other member states) for which they have no authority. This would provide a powerful incentive to fake importers' invoices, showing VAT eligible for credit instead of no VAT as under the current regime" (Cnossen 2008a: p. 9).

As an option of the 'more far-reaching measures to tackle VAT fraud', the European Commission (2008) suggests a taxation of intra-EU supplies of goods at the common EU minimum VAT rate of $15 \%$, which resembles very much the VIVAT. ${ }^{4}$ Yet, the Commission's reform model is additionally equipped with the internal correction of input-tax gap between the company that made the cross-border acquisition and the tax authority within the same country, which is caused by the difference between the national and the common 
EU VAT rates. This extra feature not only compensates the weakness of the VIVAT regarding the auditing problems of importers' invoices mentioned above but also makes the input-tax reimbursement possible according to the VAT rate and the deduction rules of destination country. ${ }^{5}$

This study attempts to put this proposal into perspective by linking it to the overall aims of value-added taxation in Europe and by comparing it to other alternative mechanisms to tax intra-Community trade as described in the literature. In particular this study focuses on the issues of bilateral revenue VAT clearing between EU member states, which would take place on the basis of a micro-model of firms' trade declarations. ${ }^{6}$

The study is structured as follows. Following this introductory part, Section 2 illustrates, based on a simple two-country model endowed with a single firm and household, the scope of VAT revenue clearing caused by the introduction of the origin principle on the B2B intra-EU supplies under the additional consideration of different VAT regimes (including a full switch to the origin principle and VIVAT). Section 3 describes the novel and distinct features of the European Commission's latest reform proposal in the same model framework and examines its advantages and shortcomings compared to the current transitional system and other previous VAT reform proposals. The final section summarises the major findings and concludes.

4 Regarding the European Commission's idea of changes in the current VAT systems as a possible option to combat against the VAT fraud, either through a generalised reverse-charge system where liability for VAT payments would be shifted from the supplier to the purchaser, or by taxing intra-Community supplies of goods, "the ECOFIN Council of 5 June 2007 also expressed the view that the preferred system of taxing intra-Community supplies should be based on taxation in the member states of departure and not in [those] of arrival ... [and] noted also that a majority of member states expressed reservations about the optional generalised reverse-charge mechanism ...” (European Commission 2008: p. 4), in which the liability for VAT is shifted from suppliers to purchasers of taxable goods and services.

5 However, this reform approach would still provide an incentive to produce false import invoices through 'third countries' in order to qualify for a tax credit. 


\section{Revenue clearing in different European VAT systems}

A switch from the destination to the origin principle applied to the intra-EU supplies would cause VAT revenue changes in the individual EU countries. In order to correct such VAT revenue imbalances among the member states and to guarantee neutrality, a clearing mechanism is necessary. In the following it is assumed that there are two countries, $A$ and $B$, and that each country has a (registered) company and a household. The intra-EU trade takes place between company $A$ and company $B$, which consists of export volume of $X_{A}$ (from $A$ to $B$ ) and $X_{B}$ (from $B$ to $A$ ), while $X_{A}>X_{B}$. Then in country $B$ the imported $X_{A}$ is further sold to household $B$ without any value added made by the domestic company $B$. The same process occurs with $X_{B}$ in country $A$. The (standard) VAT rate imposed on these 'domestic' sales amounts to $t_{A}$ in country $A$ and $t_{B}$ in country $B$, while $t_{A}>t_{B}>0$.

Figure 1 Intra-EU trade and destination principle

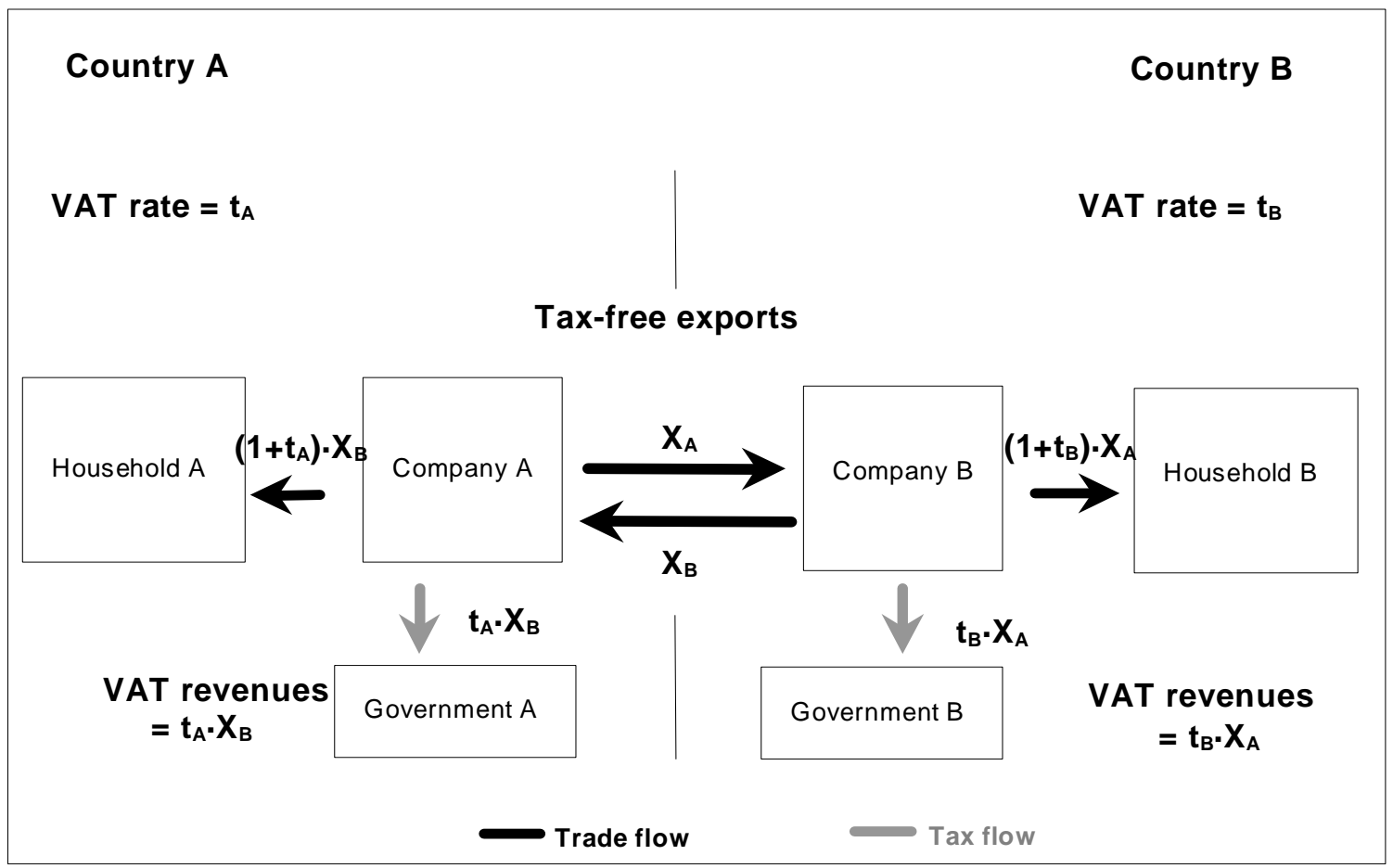

6 According to the European Commission (2008), EU countries would become dependent on each other for around 30 billion euros of VAT revenue - approximately $10 \%$ of total receipts. The Netherlands, Germany, Belgium and Ireland would emerge as the largest net contributors to the clearing system. For the bilateral micro-clearing, there are three options for gathering such microeconomic data: collection by means of (i) the normal VAT declaration, (ii) a monthly recapitulative statement with global amounts for customer/supplier, and (iii) a monthly recapitulative statement at invoice level by suppliers and purchasers. The Commission prefers the second option. 
As illustrated in Figure 1, the B2B cross-border supplies are tax free in the present transitional regime. Moreover, in country A the final consumption of the imported goods from country $B\left(X_{B}\right)$ bears the VAT burden with an own tax rate of $A\left(t_{A}\right)$. Consequently, when the destination principle prevails, the total VAT revenue for government of country $A$ amounts to

$$
T_{A, D E S}=t_{A} \cdot X_{B}
$$

Analogously for government $B$ the following applies:

$$
T_{B, D E S}=t_{B} \cdot X_{A}
$$

Under the origin principle, treating domestic and intra-EU sales alike, exports from country $A$ to country $B\left(X_{A}\right)$ are subject to $t_{A}$ and initially generate VAT revenue for government $A$ amounting to $t_{A} \cdot X_{A}$ (see Figure 2). In addition, the final consumption of the imported goods from country $B\left(X_{B}\right)$ bears the VAT burden with $t_{A}$ in country $A$. Yet company $A$ is entitled to deduct the VAT sum paid to company $B\left(t_{B} \cdot X_{B}\right)$ when importing the volume of $X_{B}$ from country $B$, and such VAT credits are granted in the destination country A.

The total VAT revenue for government $A$ now amounts to

$$
T_{A, O R I}=t_{A} \cdot X_{B}+\left(t_{A} \cdot X_{A}-t_{B} \cdot X_{B}\right)=T_{A, D E S}+\left(t_{A} \cdot X_{A}-t_{B} \cdot X_{B}\right)
$$

In a similar way one can also yield for government $B$

$$
T_{B, O R I}=t_{B} \cdot X_{A}-\left(t_{A} \cdot X_{A}-t_{B} \cdot X_{B}\right)=T_{B, D E S}-\left(t_{A} \cdot X_{A}-t_{B} \cdot X_{B}\right)
$$

Movement from the destination to the origin principle alters the level of VAT revenues of the individual countries $A$ and $B$. Since $t_{A} \cdot X_{A}>t_{B} \cdot X_{B}$, a clearing of the total amount of $\left(t_{A} \cdot X_{A}-t_{B} \cdot X_{B}\right)$ should take place between government $A$ and government $B$ in order to safeguard the revenue neutrality. 
Figure 2 Intra-EU trade and pure origin principle

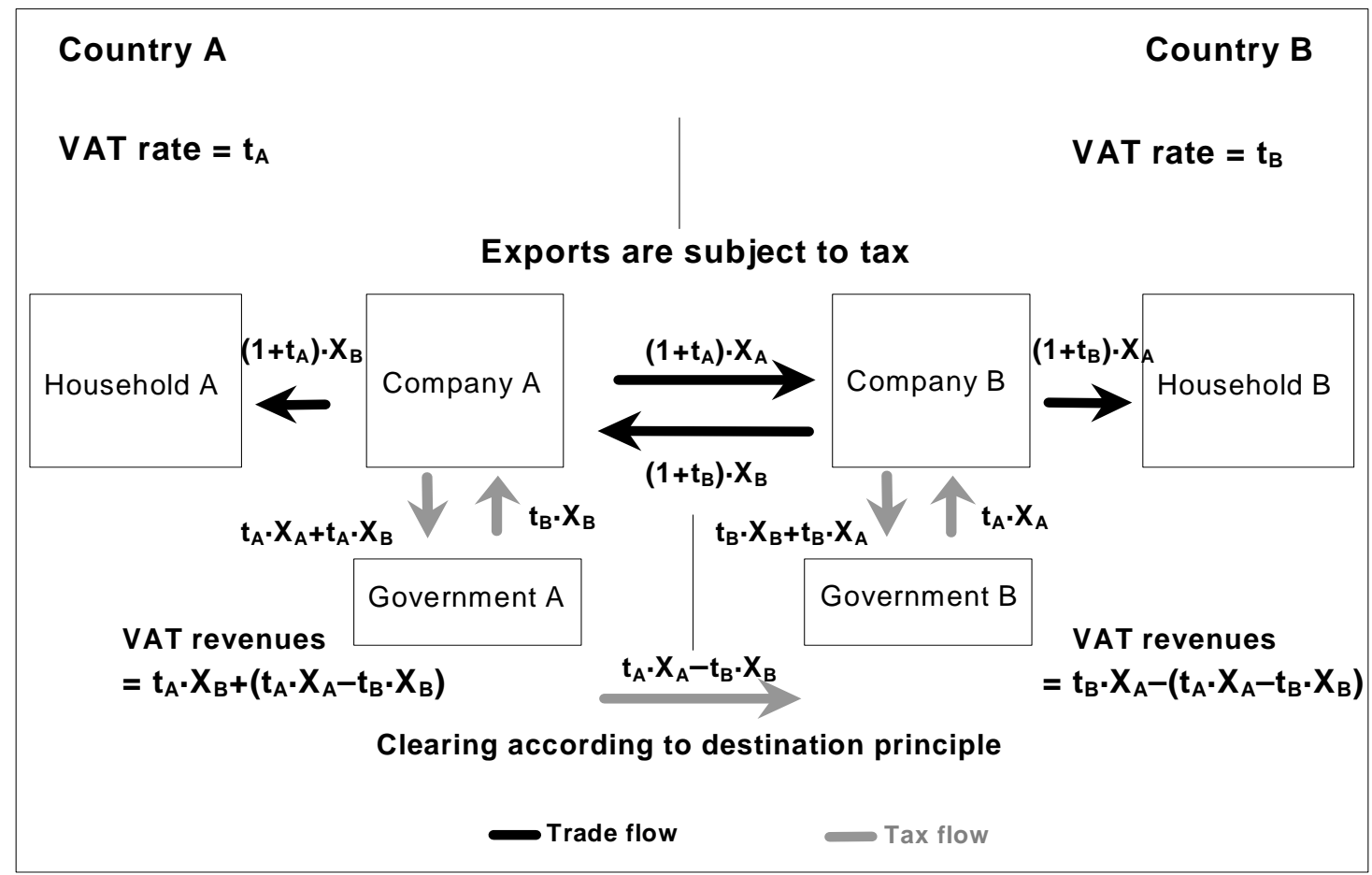

Under the VIVAT, a common EU VAT rate $\left(t^{*}>0\right)$ is imposed on the B2B cross-border supplies between country $A$ and $B$ based on the origin principle, while sales to domestic customers (i.e. household $A$ and $B$ ) are subject to the national VAT rate (i.e. $t_{A}$ and $t_{B}$ ). In this framework company A can claim, for example, EU VAT credits on intra-EU acquisition from company B $\left(t^{*} \cdot X_{B}\right)$ from government $A$, while company $B$ can claim $t^{*} \cdot X_{A}$ from government $B$.

Consequently, when the VIVAT is implemented, the total VAT revenue for government A reaches

$$
T_{A, I N T}=t_{A} \cdot X_{B}+t^{*} \cdot\left(X_{A}-X_{B}\right)=T_{A, D E S}+t^{*} \cdot\left(X_{A}-X_{B}\right)
$$

while for government $B$ the following applies:

$$
T_{B, I N T}=t_{B} \cdot X_{A}-t^{*} \cdot\left(X_{A}-X_{B}\right)=T_{B, D E S}-t^{*} \cdot\left(X_{A}-X_{B}\right)
$$

As expressed by equation (5) and (6), the introduction VIVAT should also be accompanied by a clearing system in which the total sum of $t^{*} \cdot\left(X_{A}-X_{B}\right)$ would be transferred from 
government $A$ to government $B$. In the context of such a cross-border fiscal transfer, revenue neutrality is ensured for both countries (see Figure 3).

Figure 3 Intra-EU trade and VIVAT

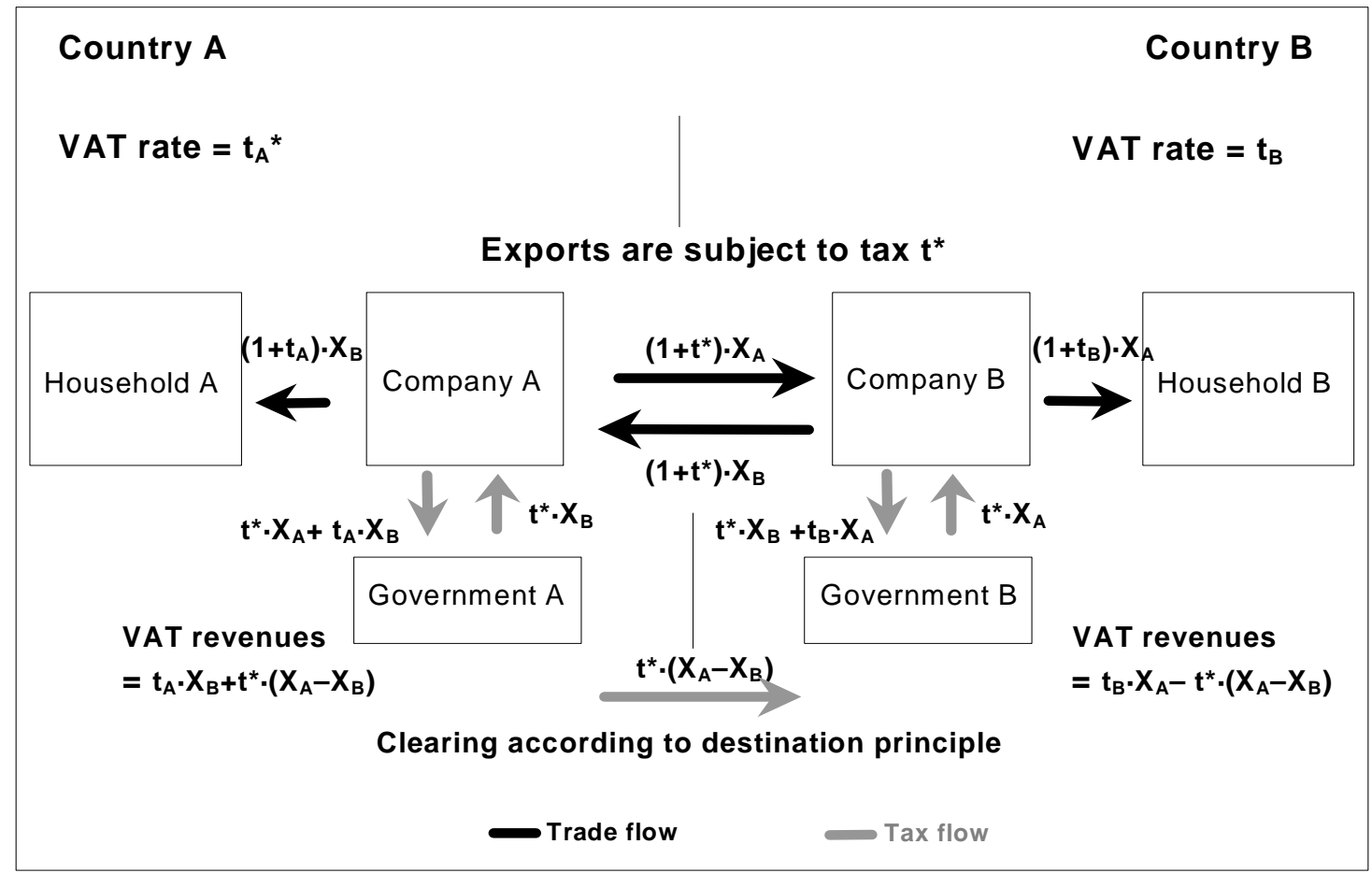

\section{European Commission's VAT reform proposal with a bilateral clearing}

In the following the major features of the European Commission's VAT reform model are introduced in more detail based on the same two-country model framework. The current, transitional VAT system remains basically applicable except where specified differently below. Company $A$ (or company $B$ ) making an intra-EU supply charges, at a common rate $\left(t^{*}\right)$ of $15 \%$, VAT to his counterpart in another EU country. As is the case in most member states the standard VAT rate $t_{A}$ and $t_{B}$ are assumed to be larger than $t^{*}$. Therefore

$$
t_{A}>t_{B}>t^{*} \text { where } t^{*}>0
$$


Yet, in order to guarantee the neutrality of the system the purchasing company declares, in cases where the country is not entitled to deduct the VAT in full, an intra-EU acquisition in the country of arrival (destination) and accounts for the VAT difference that occurs, either positive or negative, between $t^{*}$ charged on the operation and the domestic rate applicable in that country. In this context a type of (internal) input tax clearing takes place between the company and the government within the same country. In our example shown in Figure 4 such correction amounts to $\left(t_{A}-t^{*}\right) \cdot X_{B}$ for company $A$, while the sum reaches $\left(t_{B}-t^{*}\right) \cdot X_{A}$ for company $B$.

The purchaser is now entitled to deduct the VAT he has paid to his supplier and the VAT he has accounted for because of the rate difference via the VAT return and according to the right-of-deduction rules of the country of arrival ("internal clearing”). As a consequence, company $A$ can deduct $t_{A} \cdot X_{B}\left(=t^{*} X_{B}+\left(t_{A}-t^{*}\right) \cdot X_{B}\right)$, while for company $B$ the sum amounts to $t_{B} \cdot X_{A}\left(=t^{*} X_{A}+\left(t_{B}-t^{*}\right) \cdot X_{A}\right)$. Under all circumstances the purchaser needs to have an invoice from the supplier before being allowed to exercise his right of deduction. ${ }^{7}$

Hence, the VAT revenue for government $A$ now amounts to

$$
T_{A, E C}=t_{A} \cdot X_{B}+t^{*} \cdot\left(X_{A}-X_{B}\right)=T_{A, D E S}+t^{*} \cdot\left(X_{A}-X_{B}\right)
$$

while for government $B$ the following applies:

$$
T_{B, E C}=t_{B} \cdot X_{A}-t^{*} \cdot\left(X_{A}-X_{B}\right)=T_{B, D E S}-t^{*} \cdot\left(X_{A}-X_{B}\right)
$$

Since $T_{A, E C}>T_{A, D E S}$ and $T_{B, E C}<T_{B, D E S}$, a (cross-border) bilateral clearing mechanism is again necessary between the involved member countries to ensure that the VAT receipts accrue to the country where the intra-EU acquisition has taken place. As the case with the VIVAT, the sum of $t^{*} \cdot\left(X_{A}-X_{B}\right)$ should also be transferred from government $A$ to government $B$ in this integrated reform model, aimed at achieving revenue neutrality.

Ceteris paribus when $t^{*}$ becomes lower, the aforementioned internal input-tax clearing within a country occurs in a larger scale, while the member states' revenue dependency on 
the cross-border clearing sum declines. Under the condition $t^{*}=0$, that is equivalent to the application of destination principle, or $X_{A}=X_{B}$, no bilateral clearing mechanism is necessary between the involved countries $A$ and $B$.

Figure 4 Intra-EU trade and EU recommendation for exporter rating and bilateral clearing

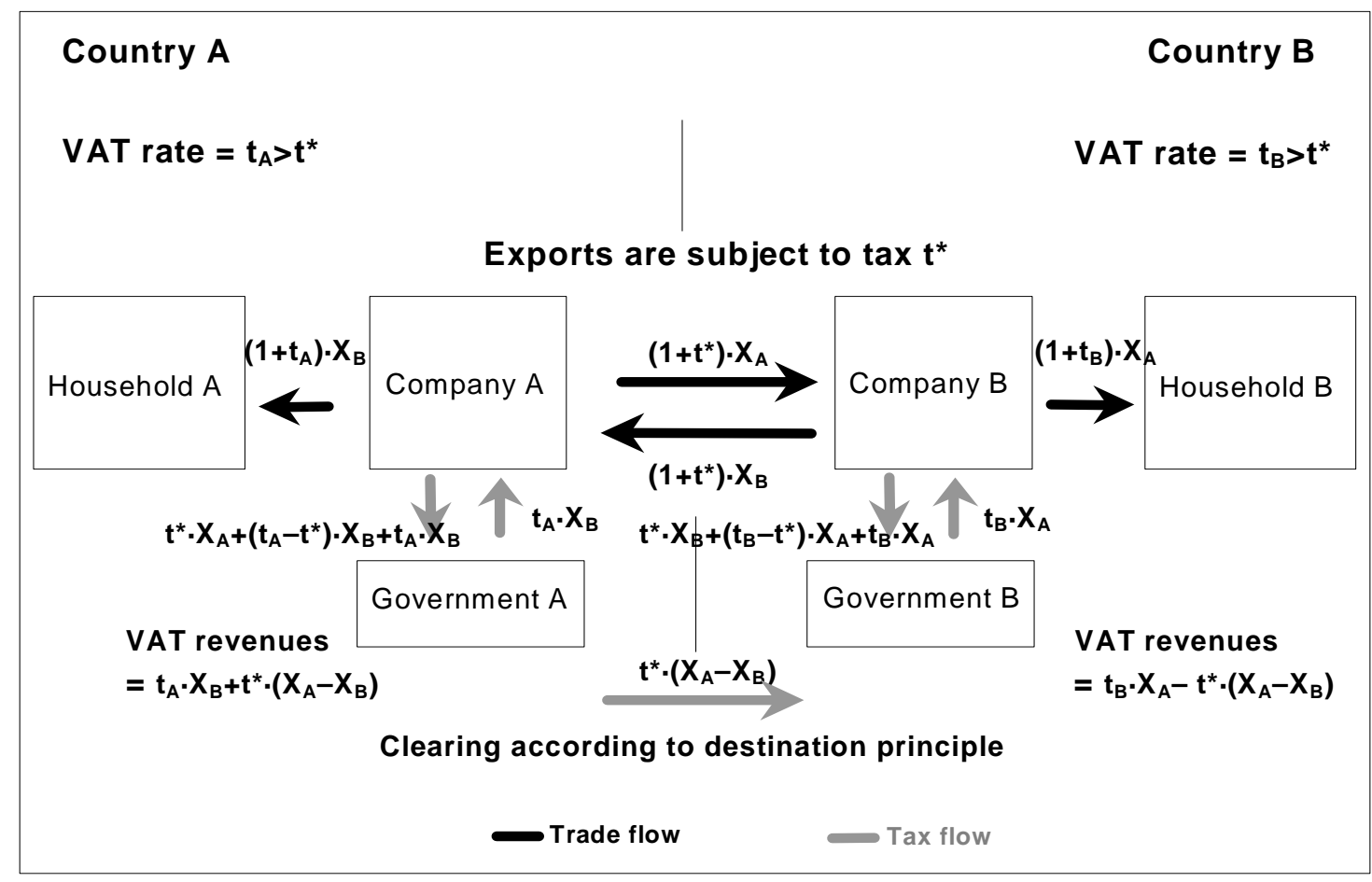

With this reform proposal the European Commission has shown its intention to lay aside its preference for compliance symmetry and tolerate the different tax treatment of domestic and intra-EU supplies within an integrated transitional VAT system. The introduction of exporter rating to the intra-EU supplies with a common EU minimum VAT rate of 15\% additionally equipped with the internal correction of input-tax gap between an importer and his own national tax authority, which is caused by the national VAT rate differing from the common rate of $15 \%$, can be seen as an improvement of the VIVAT. This extra

\footnotetext{
7 In other words, linking supply and acquisitions listings is a crucial prerequisite for the success of this reform model, which is also necessary to respond to the inherent risk of deduction without a corresponding payment. "As a further step, and [also ...] to minimise the number of mismatches between these listings, it could be an option to change the rules governing the time the tax becomes chargeable, and to link it entirely to the issuing the invoice insofar as the VAT becomes due in any case if an invoice has not been issued within a certain period” (European Commission 2008: p. 5).
} 
feature in the system would more effectively induce companies to declare their intra-EU acquisitions at home and reduce the possibilities of faking import invoices within the EU. In this context the member states would also be better able to collect microeconomic data required for the revenue clearing from taxable persons in the countries of departure and those of arrival of goods. However, such a supplement appears to make the entire VAT coordination more complicated, requiring higher compliance and administrative costs.

Concerning the internal clearing mentioned above, the choice of the common EU VAT rate $t^{*}$ seems to be a critical matter. For instance, if $t^{*}$ is set much higher than the national VAT rate (say $t^{*}=30 \%$ ), the system would ceteris paribus provide stronger incentives for firms to declare their intra-EU acquisitions, since they would additionally get money back from their own national tax authority. Moreover, the dependence of VAT revenues in a form of transfers from foreign countries would increase, which would, however, make the individual countries more active in the improvement of tax administration and its crossborder coordination in the EU. On the other hand, such a higher VAT on intra-EU supplies might induce traders to purchase lower-rated domestic commodities over high-rated imports, even though the import VAT would be fully creditable and refundable, if required.

The supranational (macro as well as micro) VAT revenue clearing system has been judged to be inappropriate for the purpose of VAT coordination in the EU (see also Genser 2003; Gebauer, Nam and Parsche 2005). Instead, a new concept of bilateral clearing system between the member states is recommended, following the subsidiarity principle. Apart from enhancing the incentive compatibility, this proposal more strongly underscores that VAT administration and revenue collection are exclusively a national matter. It also means that each country would be involved in 26 different bilateral clearing processes in the case that the number of member states remains unchanged. In other words, a total number of 351 bilateral clearings would take place in the EU 27 simultaneously. In this context, in addition to an intensive cooperation and information exchange between nations, an EU-wide coordination and harmonisation of procedures and practices related to VAT administration, declaration, collection, monitoring, auditing, etc. appears to be still required in order to make the entire clearing mechanism more transparent and efficient (see also European Commission 2007).

In order to justify the effectiveness and superiority of the VAT reform recommendation the European Commission should thoroughly evaluate benefits and costs related to its in- 
troduction. ${ }^{8}$ In particular the Commission should make it clear whether the potential to combat VAT fraud is worth the additional administrative costs and complications raised by the need for revenue clearing. The answer to this question will partly depend on the current extent of VAT fraud and on the extent to which this fraud can be eliminated by the proposal. In this context, it should be borne in mind that the recent Commission's VAT reform model primarily targets the prevention of carousel fraud. Yet there are other types of VAT fraud including (i) shadow economy fraud, (ii) suppression fraud, (iii) insolvency fraud and (iv) bogus traders (Cnossen 2008a). ${ }^{9}$ According to the data collected by Cnossen (2008a), the 'shadow economy' and the 'artificial tax avoidance (including insolvency fraud)' were the major reasons for VAT revenue losses in Germany, comprising shares of ca. $50 \%$ and $21 \%$ of total revenue losses for the period 2001-02, while the carousel fraud amounted to around $10 \%$ in the same period of time. In the UK, the share of total VAT revenue loss caused by the carousel fraud was estimated to be around $12 \%$ for $2006-07$, indicating the fact that the VAT revenue loss associated with the carousel fraud is only a fraction of the total VAT frauds committed in the individual EU member states.

Repeatedly, an important prerequisite for the implementation of such a bilateral clearing is that the discrepancy between the total intra-EU imports and exports made by the two involved countries should in essence be zero, which would be derived on the basis of firms' intra-EU trade declarations. Yet, according to the European Commission (2008), the total amount of excess of total (recorded) intra-EU imports over exports reached approximately $€ 80$ billion in 2006 in the EU. The reasons for such a mismatch also "include the level of estimation by member states of non-submitted returns; errors on the returns; threshold under which statements are not required; territorial issues; and the inclusion of goods for onward processing” (European Commission 2008: p. 14).

One of the major reasons why the consideration of introducing supranational micro as well as macroeconomic clearings has been in vain is the failure of correct measurement of

8 The major criticism of the introduction of the VAT reverse charge system in Germany was the large scale excess of anticipated short- and medium-term costs over the potential benefits (Gebauer, Nam and Parsche, 2007).

9 The first type of VAT fraud generally comprises many individuals rendering various services tax-free, often by using and buying taxable inputs from their own or employer's business. The second fraud type occurs typically when firms understate their sales or inflate their claims for VAT on purchases. The insolvency fraud takes place when firms buy taxable goods and sell them further at inflated prices, providing high tax credits to purchasers, but declare its insolvency without paying their VAT liabilities. In the case of the fourth type, fraudsters register for VAT, make false claims for input-tax reimbursement from the tax authority and then disappear (Cnossen 2008a). 
the volume of intra-EU trade on the national level. Since clear information on tax rates in the member states prevails, the European VAT coordination including the movement from destination to origin principle would also be feasible if such high quality intra-EU trade data were available in the EU. To a large extent this would also be the result of the minimised VAT evasion in the EU. In this context, Cnossen (2008a) correctly points out that a proper domestic and multi-jurisdictional audit aimed at better identifying the true intra-EU trade volume would well obviate the need for costly design change of VAT system, accompanied by reporting requirements, which might be more burdensome than those under the prevailing deferred payment. Moreover, the optimal exploitation of current legal and administrative cooperation arrangements made among member countries appears to be more effective in handling the cross-border VAT evasion than the implementation of a new reform model with the exporter rating.

\section{Conclusion}

This study examines the EU's ongoing efforts aimed at searching for an efficient European VAT system that fits its single market concept. Unfortunately the previous attempts have been unable to achieve a satisfactory solution, which calls for a reopening of public discussions and policy actions on this matter in the EU. The European Commission's recent VAT reform model, applying the exporter pricing to the intra-EU supplies with a common EU minimum rate (15\%), would compensate for the weakness of the deferred payment system which breaks the VAT chain and causes VAT fraud in a single market, and allows the different tax treatment of domestic and intra-EU supplies. The additional provision of an internal correction of the input-tax gap between an importer and his own national tax authority, which is caused by the national VAT rate differing from the common EU rate, would largely compensate for the weakness of the VIVAT: this novel feature would more effectively lead companies to declare their intra-EU acquisitions at home and reduce the possibilities of manipulating import invoices within the EU. Consequently the EU countries would also be better able to gather microeconomic data required for revenue clearing from taxable persons in both countries of departure and arrival of goods. However, apart from the incentives still provided for producing false import invoices through third countries, which are aimed at qualifying for a tax credit, the European Com- 
mission's reform approach is likely to make the entire VAT coordination more complicated, requiring higher compliance and administrative costs. Moreover, the choice of a common VAT rate appears to be critical, since a higher common rate than the national one would encourage firms to declare their intra-EU acquisitions but lead them to buy lowerrated domestic goods over higher-rated imports, while the national VAT revenues would become more strongly dependent upon the clearing system.

Instead of a less-incentive supranational VAT revenue clearing system, a bilateral one is recommended on the basis of firms' intra-EU trade declarations as mentioned above. Such a bilateral clearing method would further stimulate not only the member countries' efforts aimed at enhancing their technical and organisational tax administration as well as revenue collection systems but also the EU-wide cooperation in the field of information exchange and harmonisation of VAT procedures. However, a challenging aspect is that each country would be involved in 26 different bilateral clearing processes simultaneously in the EU 27, a number which may grow gradually.

In order to further examine the applicability of the Commission's recent VAT reform recommendation, a thorough ex ante evaluation of benefits and costs related to its introduction is necessary. Especially the Commission should make it clear whether the potential to combat VAT fraud is worth the additional administrative costs and complications raised by the need for revenue clearing. To be sure this will depend on the current extent of VAT fraud and on the extent to which this fraud can be eliminated by the proposal. In this context it should be repeatedly emphasised that the Commission's reform model primarily targets the prevention of carousel fraud and that the VAT revenue loss associated with this fraud type appears to be only a fraction of the total VAT frauds committed in the individual EU member states. Other types of VAT fraud like shadow economy fraud, suppression fraud, insolvency fraud and bogus traders can hardly be tackled by this reform proposal.

The failure of VAT coordination in the EU mainly originates from the failure of a correct measurement of the volume of intra-EU exports and imports on the national level. For example, a smooth movement from destination to origin principle would be feasible if high quality intra-EU trade data were available in the EU. Certainly this would also be the result of the minimised VAT evasion in the EU. In this context a proper domestic and multi-jurisdictional audit aimed at identifying the true intra-EU trade volume seems to obviate the need for a costly design change of VAT system, equipped with more burden- 
some reporting requirements than those under the current deferred payment. Furthermore, the optimal exploitation of legal and administrative cooperation arrangements (in the fields of tax administration, declaration, collection, monitoring, etc.) made among member countries would eventually be more promising to handle the cross-border VAT evasion than the introduction of exporter ratings.

\section{References}

Bird, R. and P.-P. Gendron (2000), “CVAT, VIVAT and Dual VAT: Vertical Sharing and International Trade”, International Tax and Public Finance 7, 753-61.

Cnossen, S. (2008a), "VAT Coordination in the European Unison: It's the Break in the Audit Trail, Stupid!”, presented at the Conference on Value Added Taxation Organised by the American Tax Policy Institute to be held in Washington DC in 2009.

Cnossen, S. (2008b), "VAT Coordination Issues in the European Union”, Commentary on the Mirrlees Review Paper on VAT and Excises, Institute for Fiscal Studies, http://www.ifs.org.uk/mirrleesreview/commentaries/cnossen_commentary.pdf.

European Commission (1996), “A Common System of VAT: A Programme for the Single Market”, COM(1996), 328 final, Brussels.

European Commission (2007), "Communication from the Commission to the Council Concerning Some Key Elements Contributing to the Establishment of the VAT Antifraud Strategy within the EU”, COM(2007) 758 final, Brussels.

European Commission (2008), “On Measures to Change the VAT System to Fight Fraud”, Commission Staff Working Paper, SEC(2008) 249, Brussels.

Gebauer, A., C. W. Nam and R. Parsche (2005), "VAT Evasion and Its Consequence for Macroeconomic Clearing in the EU”, Finanzarchiv 61, 462-87.

Gebauer, A., C. W. Nam and R. Parsche (2007), "Can Reform Models of Value Added Taxation Stop the VAT Evasion and Revenue Shortfalls in the EU?”, Journal of Economic Policy Reform 10, 1-13.

Genser, B. (2003), “Coordinating VATs between EU Member States”, International Tax and Public Finance 10, 735-52.

Keen, M. and S. Smith (2000), "Viva VIVAT!”, International Tax and Public Finance 7, 741-51. 
Lockwood, B., D. de Meza and G. Myles (2005), “On the European Union VAT Proposal: The Superiority of Origin Principle over Destination Taxation”, Fiscal Studies 16, 1-17. 


\section{CESifo Working Paper Series}

for full list see www.cesifo-group.org/wp

(address: Poschingerstr. 5, 81679 Munich, Germany, office@cesifo.de)

2709 Jon H. Fiva and Gisle James Natvik, Do Re-election Probabilities Influence Public Investment?, July 2009

2710 Jarko Fidrmuc and Iikka Korhonen, The Impact of the Global Financial Crisis on Business Cycles in Asian Emerging Economies, July 2009

2711 J. Atsu Amegashie, Incomplete Property Rights and Overinvestment, July 2009

2712 Frank R. Lichtenberg, Response to Baker and Fugh-Berman's Critique of my Paper, "Why has Longevity Increased more in some States than in others?", July 2009

2713 Hans Jarle Kind, Tore Nilssen and Lars Sørgard, Business Models for Media Firms: Does Competition Matter for how they Raise Revenue?, July 2009

2714 Beatrix Brügger, Rafael Lalive and Josef Zweimüller, Does Culture Affect Unemployment? Evidence from the Röstigraben, July 2009

2715 Oliver Falck, Michael Fritsch and Stephan Heblich, Bohemians, Human Capital, and Regional Economic Growth, July 2009

2716 Wladimir Raymond, Pierre Mohnen, Franz Palm and Sybrand Schim van der Loeff, Innovative Sales, R\&D and Total Innovation Expenditures: Panel Evidence on their Dynamics, July 2009

2717 Ben J. Heijdra and Jochen O. Mierau, Annuity Market Imperfection, Retirement and Economic Growth, July 2009

2718 Kai Carstensen, Oliver Hülsewig and Timo Wollmershäuser, Price Dispersion in the Euro Area: The Case of a Symmetric Oil Price Shock, July 2009

2719 Katri Kosonen and Gaëtan Nicodème, The Role of Fiscal Instruments in Environmental Policy, July 2009

2720 Guglielmo Maria Caporale, Luca Onorante and Paolo Paesani, Inflation and Inflation Uncertainty in the Euro Area, July 2009

2721 Thushyanthan Baskaran and Lars P. Feld, Fiscal Decentralization and Economic Growth in OECD Countries: Is there a Relationship?, July 2009

2722 Nadia Fiorino and Roberto Ricciuti, Interest Groups and Government Spending in Italy, 1876-1913, July 2009

2723 Andreas Wagener, Tax Competition, Relative Performance and Policy Imitation, July 2009 
2724 Hans Fehr and Fabian Kindermann, Pension Funding and Individual Accounts in Economies with Life-cyclers and Myopes, July 2009

2725 Ernesto Reuben and Arno Riedl, Enforcement of Contribution Norms in Public Good Games with Heterogeneous Populations, July 2009

2726 Kurt Schmidheiny and Marius Brülhart, On the Equivalence of Location Choice Models: Conditional Logit, Nested Logit and Poisson, July 2009

2727 Bruno S. Frey, A Multiplicity of Approaches to Institutional Analysis. Applications to the Government and the Arts, July 2009

2728 Giovanni Villani, A Strategic R\&D Investment with Flexible Development Time in Real Option Game Analysis, July 2009

2729 Luca Di Corato and Michele Moretto, Investing in Biogas: Timing, Technological Choice and the Value of Flexibility from Inputs Mix, July 2009

2730 Gilad D. Aharonovitz, Nathan Skuza and Faysal Fahs, Can Integrity Replace Institutions? Theory and Evidence, July 2009

2731 Michele Moretto and Sergio Vergalli, Managing Migration through Conflicting Policies: an Option-theory Perspective, July 2009

2732 Volker Nitsch, Fly or Cry: Is Airport Noise Costly?, July 2009

2733 Francesco Cinnirella and Joachim Winter, Size Matters! Body Height and Labor Market Discrimination: A Cross-European Analysis, July 2009

2734 Samuel Bowles and Sandra Polanía Reyes, Economic Incentives and Social Preferences: A Preference-based Lucas Critique of Public Policy, July 2009

2735 Gary Burtless, Lessons of the Financial Crisis for the Design of National Pension Systems, July 2009

2736 Helmuth Cremer, Firouz Gahvari and Pierre Pestieau, Fertility, Human Capital Accumulation, and the Pension System, July 2009

2737 Hans Jarle Kind and Frank Stähler, Market Shares in Two-Sided Media Industries, July 2009

2738 Pamela Campa, Alessandra Casarico and Paola Profeta, Gender Culture and Gender Gap in Employment, August 2009

2739 Sebastian Gechert, Supplementary Private Health Insurance in Selected Countries: Lessons for EU Governments?, August 2009

2740 Leif Danziger, Endogenous Monopsony and the Perverse Effect of the Minimum Wage in Small Firms, August 2009 
2741 Yan Dong and John Whalley, A Third Benefit of Joint Non-OPEC Carbon Taxes: Transferring OPEC Monopoly Rent, August 2009

2742 Valentina Bosetti, Carlo Carraro and Massimo Tavoni, Climate Change Mitigation Strategies in Fast-Growing Countries: The Benefits of Early Action, August 2009

2743 Christina Felfe, The Willingness to Pay for Job Amenities: Evidence from Mothers' Return to Work, August 2009

2744 Jörg Franke, Christian Kanzow, Wolfgang Leininger and Alexandra Väth, Effort Maximization in Asymmetric N-Person Contest Games, August 2009

2745 Bruno S. Frey and Paolo Pamini, Making World Heritage Truly Global: The Culture Certificate Scheme, August 2009

2746 Frank N. Caliendo, Is Social Security behind the Collapse of Personal Saving?, August 2009

2747 Caterina Liesegang and Marco Runkel, Corporate Income Taxation of Multinationals and Fiscal Equalization, August 2009

2748 Chrysovalantou Milliou and Apostolis Pavlou, Upstream Horizontal Mergers and Efficiency Gains, August 2009

2749 Rüdiger Pethig and Christian Wittlich, Interaction of Carbon Reduction and Green Energy Promotion in a Small Fossil-Fuel Importing Economy, August 2009

2750 Kai Carstensen, Oliver Hülsewig and Timo Wollmershäuser, Monetary Policy Transmission and House Prices: European Cross-country Evidence, August 2009

2751 Olaf Posch, Explaining Output Volatility: The Case of Taxation, August 2009

2752 Beatrice Scheubel, Daniel Schunk and Joachim Winter, Don't Raise the Retirement Age! An Experiment on Opposition to Pension Reforms and East-West Differences in Germany, August 2009

2753 Daniel G. Arce, Dan Kovenock and Brian Roberson, Suicide Terrorism and the Weakest Link, August 2009

2754 Mario Larch and Wolfgang Lechthaler, Comparative Advantage and Skill-Specific Unemployment, August 2009

2755 Horst Raff and Nicolas Schmitt, Buyer Power in International Markets, August 2009

2756 Seppo Kari, Hanna Karikallio and Jukka Pirttilä, The Impact of Dividend Taxation on Dividends and Investment: New Evidence Based on a Natural Experiment, August 2009

2757 Mirco Tonin and Michael Vlassopoulos, Disentangling the Sources of Pro-social Behavior in the Workplace: A Field Experiment, August 2009 
2758 Nicole Grunewald and Inmaculada Martínez-Zarzoso, Driving Factors of Carbon Dioxide Emissions and the Impact from Kyoto Protocol, August 2009

2759 Yu-Fu Chen and Michael Funke, Booms, Recessions and Financial Turmoil: A Fresh Look at Investment Decisions under Cyclical Uncertainty, August 2009

2760 Jan-Egbert Sturm and Jakob de Haan, Does Central Bank Communication really Lead to better Forecasts of Policy Decisions? New Evidence Based on a Taylor Rule Model for the ECB, August 2009

2761 Larry Karp, Sacrifice, Discounting and Climate Policy: Five Questions, August 2009

2762 Marianna Belloc and Samuel Bowles, International Trade, Factor Mobility and the Persistence of Cultural-Institutional Diversity, August 2009

2763 Charles Noussair and Fangfang Tan, Voting on Punishment Systems within a Heterogeneous Group, August 2009

2764 Birgit Bednar-Friedl and Karl Farmer, Internationally Coordinated Emission Permit Policies: An Option for Withdrawers from the Kyoto Protocol?, August 2009

2765 Pierre M. Picard and David E. Wildasin, Labor Market Pooling, Outsourcing and Labor Contracts, August 2009

2766 Stefan Voigt and Lorenz Blume, The Economic Effects of Federalism and Decentralization - A Cross-Country Assessment, August 2009

2767 David S. Jacks, Christopher M. Meissner and Dennis Novy, Trade Booms, Trade Busts, and Trade Costs, August 2009

2768 Mario Jametti and Thomas von Ungern-Sternberg, Hurricane Insurance in Florida, August 2009

2769 Alessandro Balestrino, Kind of Black: The Musicians' Labour Market in Italy, August 2009

2770 Yosr Abid Fourati and Cathal O’Donoghue, Eliciting Individual Preferences for Pension Reform, August 2009

2771 Christian Breuer and Chang Woon Nam, VAT on Intra-Community Trade and Bilateral Micro Revenue Clearing in the EU, August 2009 